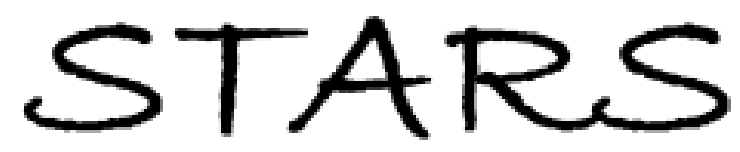

University of Central Florida

STARS

$1-1-2000$

\title{
Identification of surface chemical functional groups correlated to failure of reverse osmosis polymeric membranes
}

\author{
Sharon Beverly \\ University of Central Florida \\ Sudipta Seal \\ University of Central Florida \\ Seungkwan Hong \\ University of Central Florida
}

Find similar works at: https://stars.library.ucf.edu/facultybib2000

University of Central Florida Libraries http://library.ucf.edu

This Article; Proceedings Paper is brought to you for free and open access by the Faculty Bibliography at STARS. It has been accepted for inclusion in Faculty Bibliography 2000s by an authorized administrator of STARS. For more information, please contact STARS@ucf.edu.

\section{Recommended Citation}

Beverly, Sharon; Seal, Sudipta; and Hong, Seungkwan, "Identification of surface chemical functional groups correlated to failure of reverse osmosis polymeric membranes" (2000). Faculty Bibliography 2000s. 2436.

https://stars.library.ucf.edu/facultybib2000/2436

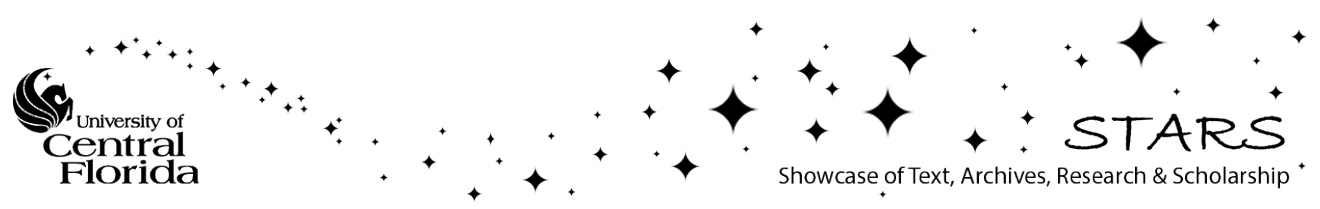




\section{Identification of surface chemical functional groups correlated to failure of reverse osmosis polymeric membranes}

Sharon Beverly, Sudipta Seal, and Seungkwan Hong

Citation: Journal of Vacuum Science \& Technology A 18, 1107 (2000); doi: 10.1116/1.582308

View online: https://doi.org/10.1116/1.582308

View Table of Contents: https://avs.scitation.org/toc/jva/18/4

Published by the American Vacuum Society

\section{ARTICLES YOU MAY BE INTERESTED IN}

WSXM: A software for scanning probe microscopy and a tool for nanotechnology

Review of Scientific Instruments 78, 013705 (2007); https://doi.org/10.1063/1.2432410

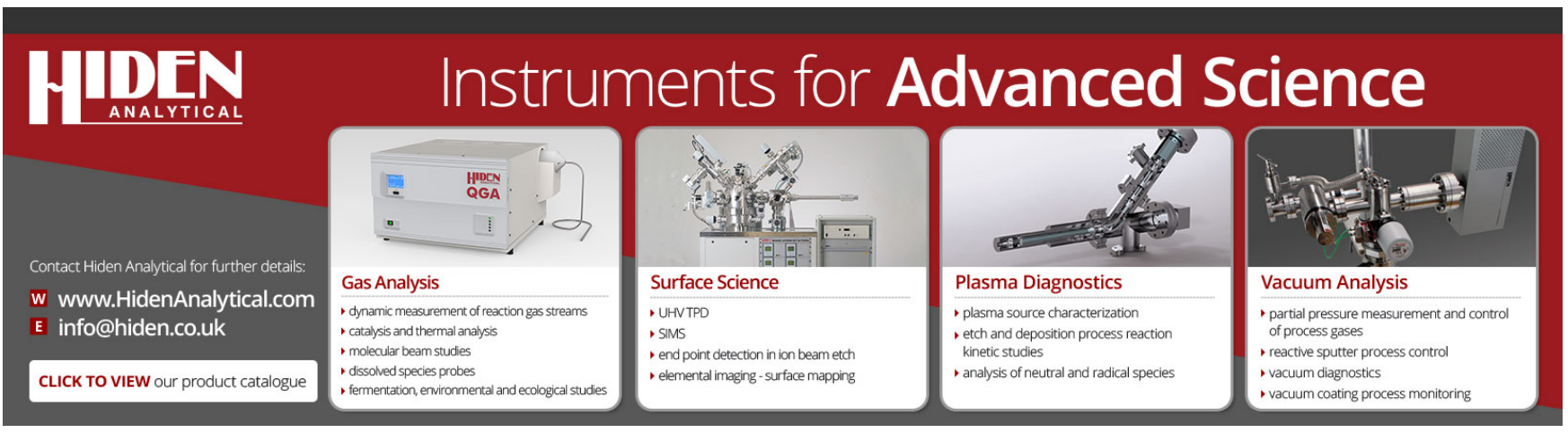




\title{
Identification of surface chemical functional groups correlated to failure of reverse osmosis polymeric membranes
}

\author{
Sharon Beverly ${ }^{\text {a) }}$ \\ Department of Civil and Environmental Engineering (CEE), University of Central Florida, \\ Orlando, Florida 32816 \\ Sudipta Seal ${ }^{\text {b) }}$ \\ Advanced Materials Processing and Analysis Center (AMPAC) and Department of Mechanical, \\ Materials and Aerospace Engineering (MMAE), University of Central Florida, Orlando, Florida 32816 \\ Seungkwan Hong ${ }^{\mathrm{c})}$ \\ Department of Civil and Environmental Engineering (CEE), University of Central Florida, \\ Orlando, Florida 32816
}

(Received 25 October 1999; accepted 14 February 2000)

\begin{abstract}
The goal of this study is to identify the causes of membrane failure observed during a 15-month operation of a low pressure reverse osmosis (RO) membrane pilot plant to treat a highly organic surface water from the Hillsborough River in Tampa, Florida, using various surface analytical techniques. Three different commercial RO membranes, made of cellulose acetate or polyamide, were used in this pilot study, and all of these membranes showed performance deterioration presumably due to membrane fouling and degradation at given experimental conditions. In order to elucidate the mechanisms of membrane failure, scanning electron microscopy with energy dispersive spectrometry (SEM/EDS), x-ray photoelectron spectroscopy (XPS), and Fourier transform infrared spectroscopy (FTIR) were performed on the surface of the polymeric RO membranes used. More specifically, molecular composition including surface functional groups were identified from XPS analysis, confirmed by FTIR, and correlated to membrane failure. In addition, surface morphology and fouling layer composition were determined by SEM/EDS. The results indicated that the cellulose acetate membrane was biologically damaged, while the polyamide membrane was compromised by chlorine oxidation. The biodegradation of cellulose acetate was evidenced by the presence of nitrogen on XPS and FTIR scans. Chlorine uptake shown in XPS and FTIR scans of used polyamide membranes was a good indicator of chemical degradation. This study demonstrated that XPS, combined with FTIR and SEM/EDS, is a valuable diagnostic tool for failure analysis of polymeric RO membranes and provides valuable information to aid the manufacturers in designing better membranes for reverse osmosis. (C) 2000 American Vacuum Society. [S0734-2101(00)09204-6]
\end{abstract}

\section{INTRODUCTION}

Rapid population expansion and industrialization require ever growing quantities of water. Unfortunately, water resources have been extensively contaminated by a variety of chemical and biological toxins. In contrast, public concern regarding the protection of human health and the environment has accelerated the legislation of more stringent regulations for drinking water. As a result, new advanced technologies processing low quality and/or saline waters have been in great demand to augment water supplies and comply with stringent regulations.

In recent years, membrane filtration such as reverse osmosis (RO) has emerged as a viable advanced drinking water treatment technology that offers a versatile approach to meeting multiple water quality objectives. ${ }^{1}$ The advantages of RO membrane technology involve not only its ability to produce water of superior quality but also its potential to reduce the size of treatment plants and to simplify water treatment

\footnotetext{
${ }^{a)}$ Electronic mail: beverly@pbworld.com

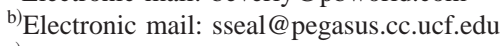

c)Electronic mail: shong@mail.ucf.edu
}

processes. $^{2}$ RO membranes are currently used worldwide to desalinate seawater and brackish waters for human consumption.

However, the application of RO membrane filtration to treat low quality waters is greatly limited by gradual deterioration of performance due to membrane fouling and degradation. ${ }^{3,4}$ Generally, membrane fouling refers to the adsorption or accumulation of retained substances within the membrane pores or on the membrane surface. Membrane fouling causes a gradual decline in productivity of membrane filtration. A wide spectrum of constituents in source waters are known to contribute to fouling. Membrane foulants are classified roughly into dissolved organic substances, colloidal or particulate matter, insoluble inorganic compounds, and biological matter such as bacteria. ${ }^{5}$ Polymeric RO membranes are also vulnerable to chemical and biological attack during operation. The chemical and biological degradation of RO membranes results in poor separation of contaminants and ultimately shortens membrane life, causing a significant increase in operation and maintenance cost. A fundamental understanding of the mechanisms of membrane fouling and degradation is of paramount importance to make this tech- 
nology more economically feasible and competitive.

The membrane research group at the University of Central Florida (UCF) has performed a pilot plant study using low pressure RO membranes to investigate the effectiveness of membrane filtration to treat low quality waters. ${ }^{6}$ The source water was a highly organic surface water obtained from the Hillsborough River in Tampa, Florida. In this study, three different low pressure RO membranes from two membrane manufacturers were systematically evaluated under various operating conditions. Because of great fouling potentials, rigorous pretreatments of feed waters were implemented including microfiltration (MF), and coagulation, sedimentation and filtration (CSF). Antiscalents and biocides were also added to prevent precipitative and biological fouling. The performance of the three membranes tested were, however, gradually deteriorated during 15 months of pilot operation, due to presumed fouling, biological and chemical degradation. Detailed operational conditions and performance data are available in a recent publication. ${ }^{6}$

This study is an attempt to identify surface functional groups and chemical changes in surfaces of RO membranes during operation, which would give clues to the nature of the membrane failure observed in the pilot study. Since the depth of the RO membrane skin layer is on the order of nanometers, ${ }^{7}$ X-ray photoelectron spectroscopy (XPS) was chosen to be an analytical tool for this investigation. In addition, scanning electron microscopy with energy dispersive spectrometry (SEM/EDS) was used to map the surface topography and Fourier transform infrared spectrometry (FTIR) was used to validate XPS results. Last, based on the surface analysis results, the possible mechanisms of membrane failures observed during the pilot membrane study were delineated.

\section{BACKGROUND}

Since the early 1960's, various types of organic membranes have been developed and some are successfully commercialized. ${ }^{8}$ For RO applications, cellulose acetate and polyamide are two major commercial organic membranes. ${ }^{9}$ The cellulose acetate polymer consists of gluco-pyranose rings connected by $\beta$-glycoside (ether) linkages. ${ }^{10}$ Hydroxyl groups of this polymer are acetylated at various degrees. The asymmetric cellulose acetate membrane is, in general, quite resistant to chemical disinfectants such as chlorine. ${ }^{3}$ But its application is limited to a narrow feed $\mathrm{pH}$ range because of polymer hydrolysis. ${ }^{11}$ Relatively low water flux and susceptibility to microbiological attack are also major drawbacks of this membrane. ${ }^{12}$

The second group of high performance organic membranes is a thin film composite polyamide membrane. In this membrane, permeate flux is improved by providing an ultrathin, cross-linked skin layer, approximately $200-500 \mathrm{~nm}$ in thickness. ${ }^{7}$ This thin layer is fabricated by interfacial polymerization and deposited on a microporous substrate, usually consisting of polysulfone. ${ }^{9}$ The resulting composite membrane contains amide or urea linkages in various stages of substitution. This membrane exhibits higher water flux and better salt rejection than the cellulose acetate membrane. This membrane also shows fairly good hydrolytic stability over a wide range of $\mathrm{pH}$. A major disadvantage of this membrane, however, is its extreme sensitivity to chemical oxidants such as chlorine. The performance of the membrane deteriorates severely even at low levels of chlorine exposure. ${ }^{3}$

\section{EXPERIMENT}

\section{A. RO membranes investigated}

Three commercial low pressure RO membranes were investigated: (i) CALP, (ii) ESNA, and (iii) LFC1. CALP is a cellulose acetate membrane and provided by Fluid Systems (San Diego, CA). ESNA and LFC1 are thin film composite polyamide membranes manufactured by Hydranautics (Oceanside, CA). These membranes are operated at significantly low pressures compared to conventional desalting RO membranes, and are often considered to be nanofiltration (NF) membranes.

During pilot operation without biocide addition (i.e., monochloramine), CALP showed a dramatic increase in water flux and zero salt rejection, indicating complete loss of membrane integrity by biodegradation. Severe irreversible fouling was observed with ESNA under similar experimental conditions. Finally, LFC1 showed a steady performance even without biocide, but gradually lost its integrity over time from the inception of monochloramine addition.

For each membrane, new and used samples were tested and compared. Each sample was thoroughly rinsed in deionized (DI) water and allowed to dry under vacuum before analysis. A baseline spectrum of each sample was taken before use to identify any changes that the membrane had undergone while in use. After drying, a battery of tests were performed as described in the following subsections.

\section{B. Methods of characterization}

\section{Scanning electron microscopylenergy dispersive spectrometry (SEMIEDS)}

All samples were analyzed using a Cambridge Model S-200 SEM attached to EDS (Oxford Instruments ISIS Unit, Cambridge, UK) to provide a qualitative and semiquantitative analysis for all elements in the Periodic Table above beryllium. Acceleration voltage was $25 \mathrm{kV}$ and working distance was $25 \pm 5 \mathrm{~mm}$. Operating pressure was $10^{-5}$ Torr at maximum. Due to extreme acceleration voltage and charging effects of the insulating membranes, the samples had to be coated in gold using a sputter coater at 0.5 Torr, $2.4 \mathrm{kV}$, and $20 \mathrm{~mA}$ for 1.5 to $3 \mathrm{~min}$. EDS is not affected by charging of sample specimens, therefore, fouling layer spectra were taken without gold coating.

\section{X-ray photoelectron spectroscopy (XPS)}

All XPS analysis was performed using a 5400 PHI ESCA spectrometer (Physical Electronics, Eden Prarie, MN). A nonmonochromated aluminum $K \alpha$ x-ray source $(h \nu$ $=1486.6 \mathrm{eV}$ ) at the power of $250 \mathrm{~W}$ was used for the analy- 


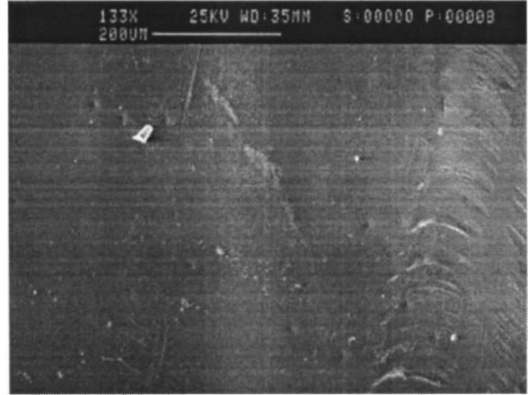

(a)

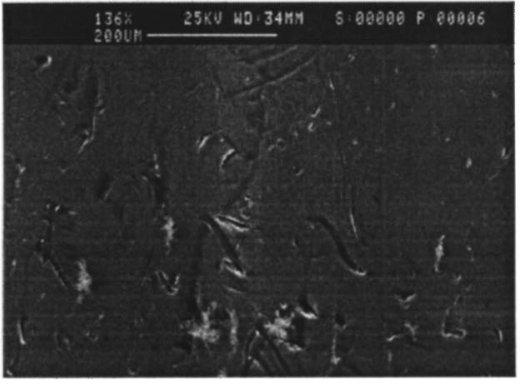

(c)

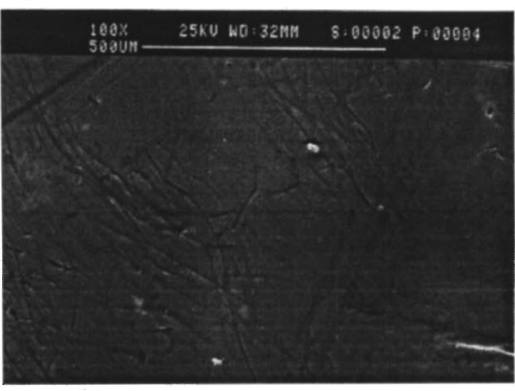

(e)

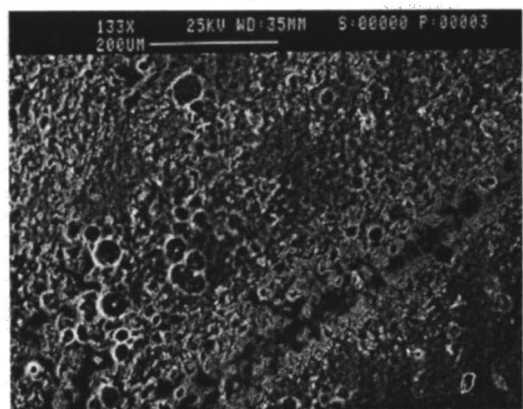

(b)

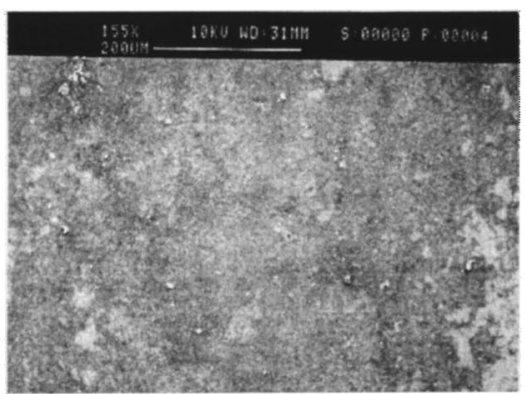

(d)

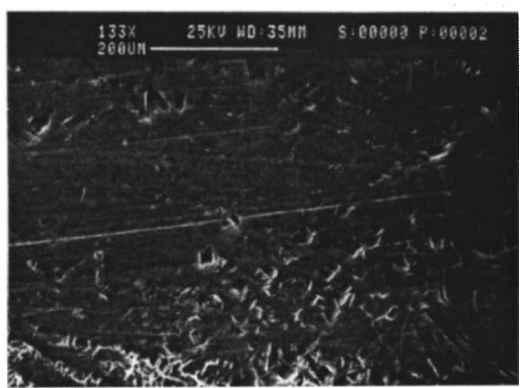

(†)
FIG. 1. SEM Micrographs of new and used membranes. (a) $133 \mathrm{X}$ image of new CALP, (b) 133X image of biodegraded CALP, (c) 136X image of new ESNA, (d) $155 \mathrm{X}$ image of fouled ESNA, (e) 100X image of new LFC1, (f) $133 \mathrm{X}$ image of degraded LFC1. sis. Acceleration voltage was $15 \mathrm{kV}$ and amperage was 12-18 mA. Spectral deconvolution was performed by first removing Shirley background and minimizing fit error using standard peak-fit software. ${ }^{13}$ The second and fourth derivatives of the spectrum were then inspected to locate position of various peaks. The core level peaks were then successfully fitted with component peaks with a Gaussian-Lorentzian distribution. It is important to note that most of the specimens in this study were fully aromatic and that the carbon $\mathrm{C}$ $(1 s)$ was at a binding energy (BE) of $285 \mathrm{eV}$, not the adventitious carbon $\mathrm{C}(1 s)$ peak at $284.6 \mathrm{eV} .{ }^{14}$ In the case of CALP, the aromatic C $(1 s)$ is placed at 285.4. ${ }^{14}$ Peaks were placed according to positions found in literature, and full width half maximum (FWHM) was also fixed. This allowed the program to fit the amplitude of the peaks.

\section{Fourier transform infrared spectroscopy (FTIR)}

All samples were prepared by separating the active layer and support layers. First, a diamond cell transmission method was used, but discrepancies between the forward and reverse sides of the active layer led to use of an attenuated total reflectance (ATR) objective only for the purpose of this study as a complement to the XPS surface technique. The FTIR was a Bio-Rad model No. 575C (Cambridge, MA).

\section{RESULTS AND DISCUSSION}

\section{A. Scanning electron microscopy/energy dispersive spectrometry}

Scanning electron microscopy has been the backbone of membrane morphology studies for years. ${ }^{15}$ SEM images of new membrane samples shown in Figs. 1(a), 1(c), and 1(e) revealed that CALP was the smoothest of the three membranes. Both LFC1 and ESNA contained a network of ridges and valleys, which were more apparent at magnifications greater than 2000X (Fig. 2). These ridges and valleys could conceivably trap organic macromolecules and inorganic colloids, such as those believed to cause severe fouling on the ESNA membrane. ${ }^{16}$ From Fig. 2, LFC1 does appear to have a smoother surface than ESNA, which may explain less foul- 


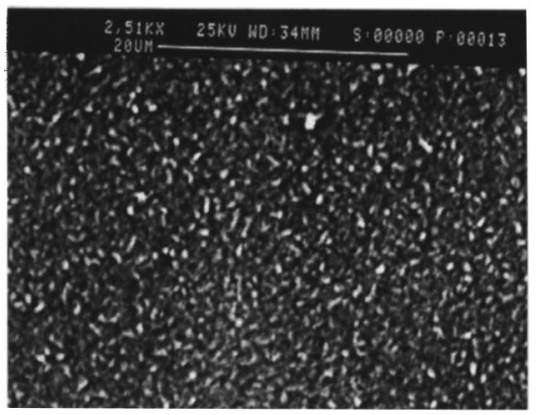

(a)

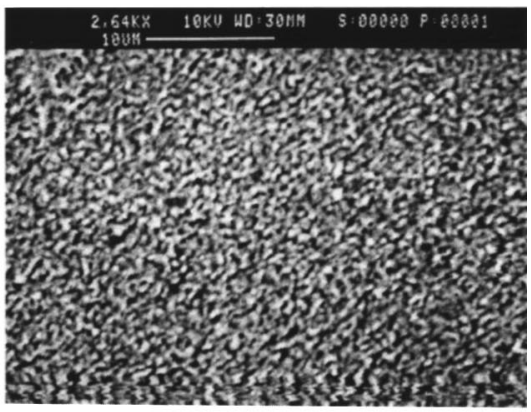

(b)
FIG. 2. Surface roughness of new ESNA and LFC1 by SEM, (a) 2500X image of new ESNA, (b) 2600X image of new LFC1. ing on LFC1 during the pilot study. Last, micrographs of the ESNA membrane support layer showed that the fibers were much looser than LFC1, allowing for deep pockets to form, some as much as $5 \mu \mathrm{m}$ wide.

SEM images of used membranes were markedly different from those of new membranes. CALP showed complete devastation by a microbial vector [Fig. 2(b)]. The multitudes of holes in the membrane could be due to separate colonies of microbes, or could be formed by the intrusion of a fungal hyphae system which are root-like structures. In some cases, the high acceleration voltage could cause holes of this nature, but this pattern was first noted under optical microscopy. Also, all membranes were prepared and tested in the same manner and none of the others showed similar holes. The micrograph of used ESNA showed a cake of colloidal particles similar to fine sand or silt [Fig. 2(d)]. This fouling layer completely occluded the active surface of the membrane. The micrograph of used LFC1 does not indicate any of the colloidal fouling that caused ESNA to fail. It should be noted that LFC1 was produced as an improvement over ESNA by Hydranautics, particularly modified for reducing fouling. There were some sections showing degradation of the LFC1 surface, including what appears to be cracking and peeling of the active layer [Fig. 2(f)].

EDS is not the technique of choice for analyzing polymers because intensities of the carbon and oxygen atoms are often erratic and misleading in organic samples such as polymer membranes. However, an EDS spectrum gives an excellent elemental analysis of the fouling layers of membranes. The presence of a certain foulant can be identified by the series of peaks shown in the EDS scan. This was the case with the biological foulant on the surface of CALP membrane. It repeatedly presented a signature of a combination of dried salts that became immediately recognizable. No such presence was found on the LFC1 membrane. This would indicate that CALP was subject to biological degradation, while LFC1 was not under the given conditions of operation.

\section{B. X-ray photoelectron spectroscopy}

Detailed chemical composition by atomic percentage of the proprietary polymeric membranes was calculated from XPS peaks and is listed in Table I. It is important to note that exact chemical structures of the membranes are proprietary and local variations can occur due to the nature of membrane manufacture. In order to avoid possible misinterpretation of membrane chemical structure due to local variations, XPS analysis was repeated for selected membranes and showed good reproducibility. XPS revealed that CALP was a cellulose acetate membrane represented for the most part by triacetate species [acetate $(\mathrm{O}-\mathrm{C}=\mathrm{O})_{\mathrm{BE}} \sim 289.7 \mathrm{eV}$ ] (Figs. 3 and 4). LFC1 showed a polyamide active layer apparently crosslinked to a polysulfone $\left[\mathrm{S}(2 p)_{\mathrm{BE}} \sim 170-168 \mathrm{eV}\right]$ infrastructure as detected from the XPS surface scan (Fig. 3).

After use in the pilot study to purify surface water, the surface scans of the membranes were remarkably different (Fig. 3). The nitrogen, sulfur, chlorine and calcium peaks were the main focus of this research. New CALP had no nitrogen substituent as detected from the surface spectrum, but a strong nitrogen presence was found in the used sample of CALP. This observation suggested that CALP had been under attack from a biological vector. The difference in the FWHM of the C $(1 s)$ peak before and after use indicated a change in amplitude of two chemical substances as well as the addition of a different species [carboxyl $(\mathrm{COOH})_{\mathrm{BE}}$ $\sim 289.4 \pm 0.15 \mathrm{eV}]$. Further investigation found the nitrogen to be linked to an amino acid $\left[\mathrm{N}(1 s)_{\mathrm{BE}} \sim 400.5 \mathrm{eV}\right]$, very similar to the digestive juices of the adsorptive/absorptive feeder found on the membrane itself (Fig. 3). Similar XPS studies have been conducted by one of the authors to identify the detailed nitrogen chemistry to identify amino acids and other amine groups in cell/silicate interaction. ${ }^{17-22}$

A series of detailed charts showing the elements and their chemical bonds as given by XPS is available in Table II. The amine group is part of the ESNA structure as indicated by $\mathrm{N}$ (1s) $\left[\mathrm{N}-\mathrm{C}=\mathrm{O}_{\mathrm{BE}} \sim 287.5-287.2 \mathrm{eV}\right]$. Used ESNA showed

TABLE I. Elements by atomic percent for each membrane.

\begin{tabular}{|c|c|c|c|c|c|c|}
\hline & \multicolumn{2}{|c|}{ LFC1 } & \multicolumn{2}{|c|}{ ESNA } & \multicolumn{2}{|c|}{ CALP } \\
\hline & New & Used $^{\mathrm{a}}$ & New & Used & New & Used \\
\hline Oxygen & 21.21 & 21.01 & 14.82 & 18.51 & 33.8 & 28.53 \\
\hline Carbon & 73.12 & 73.6 & 78.22 & 74.65 & 66.2 & 70.57 \\
\hline Nitrogen & 3.04 & 4.08 & 6.96 & 6.31 & 0 & 0.9 \\
\hline Sulfur & 2.63 & 0 & 0 & 0.12 & 0 & 0 \\
\hline Chlorine & 0 & 0.86 & 0 & 0.26 & 0 & 0 \\
\hline Calcium & 0 & 0.45 & 0 & 0.15 & 0 & 0 \\
\hline Total & 100 & 100 & 100 & 100 & 100 & 100 \\
\hline
\end{tabular}

${ }^{\text {a }}$ This membrane had been treated with monochloramine as a biocide. 

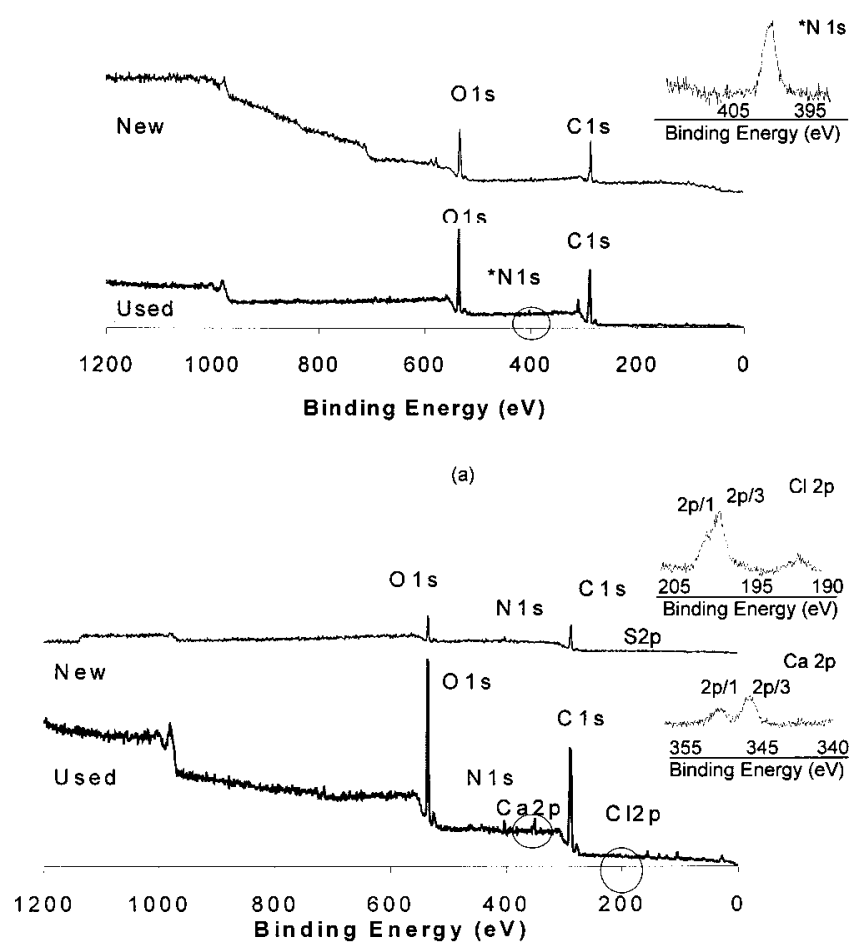

(b)

FIG. 3. (a) XPS survey spectra $(0-1200 \mathrm{eV})$ of new and used CALP, (b) XPS survey spectra $(0-1200 \mathrm{eV})$ of new and used LFC1.

evidence of chlorine uptake (Fig. 4) while used LFC1 exhibited evidence of chlorine $\left[\mathrm{Cl}(2 p 1,2 p 3)_{\mathrm{BE}}\right.$ $\sim 202.0-200.3 \mathrm{eV}]$ and calcium $\left[\mathrm{Ca}(2 p 1,2 p 3)_{\mathrm{BE}}\right.$ $\sim 350.3-346.9 \mathrm{eV}]$ on the surface after use (Fig. 4). The chlorine in $\mathrm{LFC} 1$ is present as $\mathrm{C}-\mathrm{Cl}$ bonds while the calcium is indicative of an oxide $(\mathrm{Ca}-\mathrm{O})$. An XPS scan revealing a similar chlorine presence on $\mathrm{RO}$ membranes was reported elsewhere. ${ }^{23}$

The XPS analysis of unwashed membranes showed that XPS could identify the fouling layers of the membranes as well as surface structure. Peak fitting regimens determined whether the materials discovered were foulants deposited [as indicated by the $\mathrm{N}(1 s)$ data] on the surface or materials that had become chemically bound to the surface. To be chemically bound to the surface, the foulant must show an oxidation state indicative of a bond with membrane substituents. ${ }^{14}$ If the foulant showed a chemical composition not associated with the membrane, it was determined to be lying on the surface (physisorbed) and not chemically attached. This was the case for calcium on LFC1 $\left[\mathrm{Ca} \quad(2 p 1,2 p 3)_{\mathrm{BE}}\right.$ $\sim 350.3-346.9 \mathrm{eV}]$. However, this finding does not preclude the possibility of calcium complexation with functional groups of RO membranes and further work is in progress.

\section{Fourier transform infrared spectroscopy}

FTIR identified new CALP as cellular cellulose acetate with a structure most similar to the brand name Strux CCA. ${ }^{24}$ The support layer was identified as a polyester most similar to GELBOND PAG film. This same polymer was identified

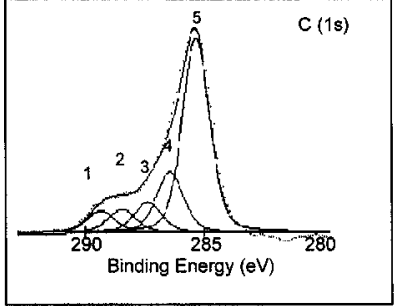

(a)

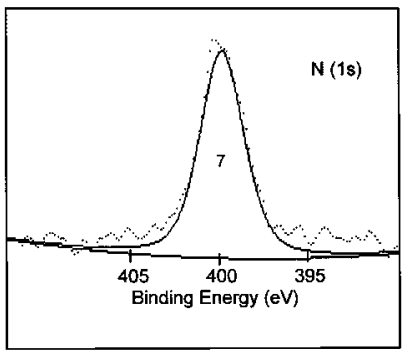

(c)

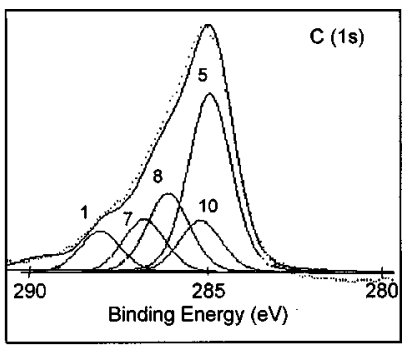

(e)

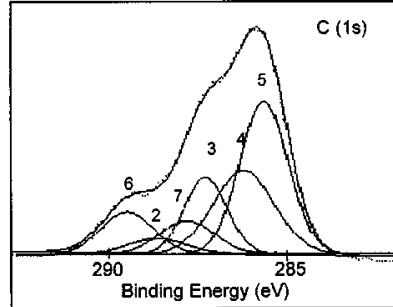

(b)

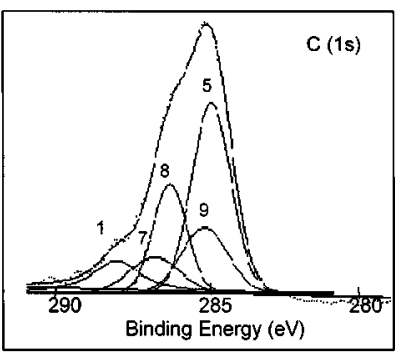

(d)

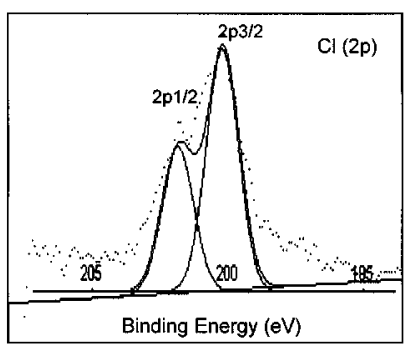

(f)

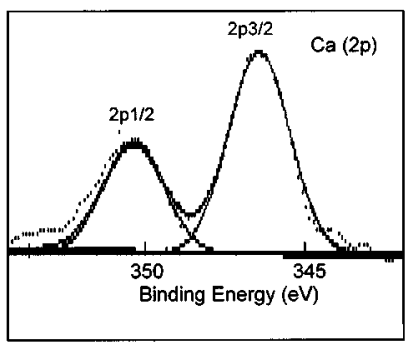

(g)

FIG. 4. Detailed XPS deconvoluted scans. (a) New CALP C $(1 s)$, (b) used CALP C $(1 s)$, (c) used CALP N $(1 s)$, (d) new LFC1 C $(1 s)$; (e) used LFC1 $\mathrm{C}(1 s)$, (f) used LFC1 $\mathrm{Cl}(2 p)$, (g) used LFC1 $\mathrm{Ca}(2 p)$. Possible peak identification: (1) $\mathrm{O}-\mathrm{C}=\mathrm{O}$, (2) $\mathrm{O}-\mathrm{C}-\mathrm{O}$, (3) $\mathrm{C}-\mathrm{O}-\mathrm{C}$, (4) $\mathrm{C}-\mathrm{C}$, (5) aromatic $\mathrm{C}-\mathrm{H}$, (6) $\mathrm{COOH}$, (7) $\mathrm{N}-\mathrm{C}=\mathrm{O}$, (8) $\mathrm{C}-\mathrm{N}$, (9) $\mathrm{C}-\mathrm{SO}_{2}$, (10) $\mathrm{C}-\mathrm{Cl}$.

for LFC1 and ESNA support layers. A Bio-Rad/Sadtler interactive atlas identified the biologically damaged CALP as a variety of polymers from polygalacturonic acid to hercose and/or celanese. The structure had changed significantly and the atlas had difficulty recognizing it. Changes in the spectra included the absence of the hydroxyl group at 3450 and 2900 $\mathrm{cm}^{-1}$ and the addition of amino acid groups at 3250 and $2000 \mathrm{~cm}^{-1}$. An overlay of the two spectra showed destruction of the initial chemical structure (Fig. 5). This destruction was due to the digestion of the membrane by microorganisms, as shown by the attack on the chair form of the 
TABLE II. Detailed XPS binding energy data of RO membranes [for C $(1 s): \pm 0.1 \mathrm{eV} ; \mathrm{N}(1 s): \pm 0.15 \mathrm{eV}$; O $(1 s): \pm 0.1 \mathrm{eV}]$.

\begin{tabular}{|c|c|c|c|c|c|c|c|}
\hline & $\begin{array}{c}\mathrm{C}(1 s) \\
\text { Binding } \\
\text { energy }\end{array}$ & State & $\begin{array}{l}\text { Total } \\
\text { FWHM }\end{array}$ & $\begin{array}{c}\mathrm{O}(1 s) \\
\text { Binding } \\
\text { energy }\end{array}$ & State & $\begin{array}{l}\mathrm{N}(1 s) \\
\text { Binding } \\
\text { energy }\end{array}$ & State \\
\hline \multirow[t]{5}{*}{ New CALP } & 289.7 & $\mathrm{O}-\mathrm{C}=\mathrm{O}^{\mathrm{d}}$ & 2.4 & 533.1 & $\mathrm{O}-\mathrm{C}-\mathrm{O}$ & & \\
\hline & 288.6 & $\mathrm{O}-\mathrm{C}-\mathrm{O}$ & & 533.8 & $\mathrm{O}^{\mathrm{a}}-\mathrm{C}=\mathrm{O}$ & & \\
\hline & 287.2 & $\mathrm{C}-\mathrm{O}-\mathrm{C}$ & & 532.4 & $\mathrm{O}-\mathrm{C}=\mathrm{O}^{\mathrm{a}}$ & & \\
\hline & 286.5 & $\mathrm{C}-\mathrm{C}$ & & & & & \\
\hline & 285.4 & $\mathrm{CH}$ & & & & & \\
\hline \multirow[t]{6}{*}{ Used CALP } & 289.4 & $\mathrm{COOH}$ & 3.1 & 534.2 & $\mathrm{COOH}$ & 400.5 & $\mathrm{~N}-\mathrm{C}=\mathrm{O}$ \\
\hline & 288.6 & $\mathrm{O}-\mathrm{C}-\mathrm{O}$ & & 533.8 & $\mathrm{O}^{\mathrm{a}}-\mathrm{C}=\mathrm{O}$ & & \\
\hline & 287.7 & $\mathrm{~N}-\mathrm{C}=\mathrm{O}$ & & 533.3 & $\mathrm{C}-\mathrm{O}-\mathrm{C}$ & & \\
\hline & 286.7 & $\mathrm{C}-\mathrm{O}-\mathrm{C}$ & & 532.4 & $\mathrm{O}-\mathrm{C}=\mathrm{O}^{\mathrm{a}}$ & & \\
\hline & 286.5 & $\mathrm{C}-\mathrm{C}$ & & 531.5 & $\mathrm{~N}-\mathrm{C}=\mathrm{O}$ & & \\
\hline & 285.4 & $\mathrm{CH}$ & & & & & \\
\hline \multirow[t]{4}{*}{ New ESNA } & 288.9 & $\mathrm{O}-\mathrm{C}=\mathrm{O}^{\mathrm{c}}$ & 2.3 & 533.9 & $\mathrm{O}^{\mathrm{a}}-\mathrm{C}=\mathrm{O}$ & 400.4 & $\mathrm{~N}-\mathrm{C}=\mathrm{O}$ \\
\hline & 287.5 & $\mathrm{~N}-\mathrm{C}=\mathrm{O}$ & & 532.6 & $\mathrm{O}-\mathrm{C}=\mathrm{O}^{\mathrm{a}}$ & & \\
\hline & 287.0 & $\mathrm{C}-\mathrm{N}$ & & 531.8 & $\mathrm{~N}-\mathrm{C}=\mathrm{O}$ & & \\
\hline & 285.0 & $\mathrm{CH}$ & & & & & \\
\hline \multirow[t]{5}{*}{ Used ESNA } & 288.7 & $\mathrm{O}-\mathrm{C}=\mathrm{O}^{\mathrm{c}}$ & 2.6 & 533.8 & $\mathrm{O}^{\mathrm{a}}-\mathrm{C}=\mathrm{O}$ & 400.4 & $\mathrm{~N}-\mathrm{C}=\mathrm{O}$ \\
\hline & 287.2 & $\mathrm{~N}-\mathrm{C}=\mathrm{O}$ & & 532.6 & $\mathrm{O}-\mathrm{C}=\mathrm{O}^{\mathrm{a}}$ & & \\
\hline & 286.7 & $\mathrm{C}-\mathrm{N}$ & & 531.6 & $\mathrm{~N}-\mathrm{C}=\mathrm{O}$ & & \\
\hline & 285.1 & $\mathrm{C}-\mathrm{Cl}$ & & & & & \\
\hline & 285.0 & $\mathrm{CH}$ & & & & & \\
\hline \multirow{5}{*}{ New LFC1 } & 288.4 & $\mathrm{O}-\mathrm{C}=\mathrm{O}^{\mathrm{c}}$ & 3 & 533.9 & $\mathrm{O}^{\mathrm{a}}-\mathrm{C}=\mathrm{O}$ & 400.4 & $\mathrm{~N}-\mathrm{C}=\mathrm{O}$ \\
\hline & 287.0 & $\mathrm{~N}-\mathrm{C}=\mathrm{O}$ & & 532.6 & $\mathrm{O}-\mathrm{C}=\mathrm{O}^{\mathrm{a}}$ & & \\
\hline & 286.6 & $\mathrm{C}-\mathrm{N}$ & & 532.9 & $\mathrm{O}=\mathrm{S}=\mathrm{O}$ & & \\
\hline & 285.5 & $\mathrm{C}-\mathrm{SO}_{2}$ & & 531.9 & $\mathrm{~N}-\mathrm{C}=\mathrm{O}$ & & \\
\hline & 285.0 & $\mathrm{CH}$ & & & & & \\
\hline \multirow[t]{5}{*}{ Used LFC1 } & 288.0 & $\mathrm{O}-\mathrm{C}=\mathrm{O}^{\mathrm{c}}$ & 3 & 533.8 & $\mathrm{O}^{\mathrm{a}}-\mathrm{C}=\mathrm{O}$ & 400.1 & $\mathrm{~N}-\mathrm{C}=\mathrm{O}$ \\
\hline & 287.2 & $\mathrm{~N}-\mathrm{C}=\mathrm{O}$ & & 532.9 & $\mathrm{O}-\mathrm{C}=\mathrm{O}^{\mathrm{a}}$ & & \\
\hline & 286.5 & $\mathrm{C}-\mathrm{N}$ & & 531.9 & $\mathrm{~N}-\mathrm{C}=\mathrm{O}$ & & \\
\hline & 285.2 & $\mathrm{C}-\mathrm{Cl}$ & & & & & \\
\hline & 285.0 & $\mathrm{CH}$ & & & & & \\
\hline
\end{tabular}

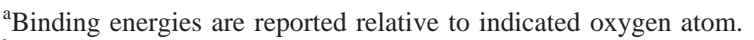

'For final fit, the "additional adjust" function was used after placing the peaks, this may shift the final peak positions by an additional $0.2-0.3 \mathrm{eV}$.

${ }^{\mathrm{c}}$ This bond is indicative of surface oxidation.

${ }^{\mathrm{d}}$ This bond denotes the acetate groups of cellulose acetate.

cellulose at the $\mathrm{OH}$ bond. Biodegradation of CALP was not surprising since cellulose acetate provides an excellent food source for biogrowth.

ESNA and LFC1 were practically identical except that the sulfonyl presence was more pronounced in LFC1. The peaks at positions 1730 and $1050 \mathrm{~cm}^{-1}$ illustrated this fact. ${ }^{25}$ FTIR scans of both LFC1 and ESNA showed peaks at 1665, 1615, and $1545 \mathrm{~cm}^{-1}$, which indicate an amide linkage. ${ }^{26}$ This amide linkage was not present in the ATR spectra of the underside of the active layer, indicating that it was attached to the outer surface only, and not a substituent throughout the active layer. It is important to note that FTIR is a deeper technique than XPS, so it may read into the polysulfone support layer, as well as cross-linking at the interface between polyamide and polysulfone.

For both ESNA and LFC1, FTIR scans of used membranes showed an absence of a sulfonyl link and the addition of chlorine as illustrated in Fig. 5. Chlorine stretching peaks occurred at $1575-1595 \mathrm{~cm}^{-1}$. The missing sulfonyl bond occurs at $1000-1050 \mathrm{~cm}^{-1}$. Typical polyamide membranes carry carboxyl or sulfonyl groups at the pendant site on the aromatic rings of the membranes. The sulfonyl group may also have been grafted to provide a stronger polymer resistant to hydrolysis. ${ }^{27}$ FTIR scans of used LFC1 suggested the electrophilic substitution of chlorine for sulfonyl groups. This may be possible because of the greater electron affinity of chlorine over sulfonyl. ${ }^{28}$

The degradation of polyamide membranes by chlorine used for feed water disinfection has been one of the major obstacles to wide use of RO membrane technology in drinking water treatment. A few studies in this area suggested that membrane failure resulted from chlorine attack on amide nitrogen and aromatic rings. ${ }^{3}$ Amide nitrogen is vulnerable to chlorine attack because of electron withdrawing effects of the carbonyl group. Aromatic rings are also susceptible to electrophilic substitution by chlorine. Ring chlorination is considered to take place by two possible reaction pathways: direct electrophilic aromatic substitution and Orton rearrangement. The Orton mechanism involves initial chlorination of amide nitrogen. The resulting N-chloro amide then undergoes intermolecular rearrangement forming various aromatic substitution products. The exact chemical mecha- 


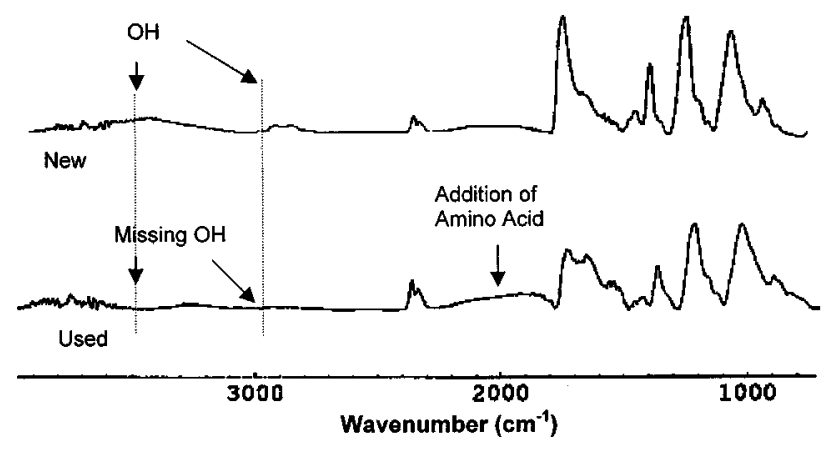

(a)

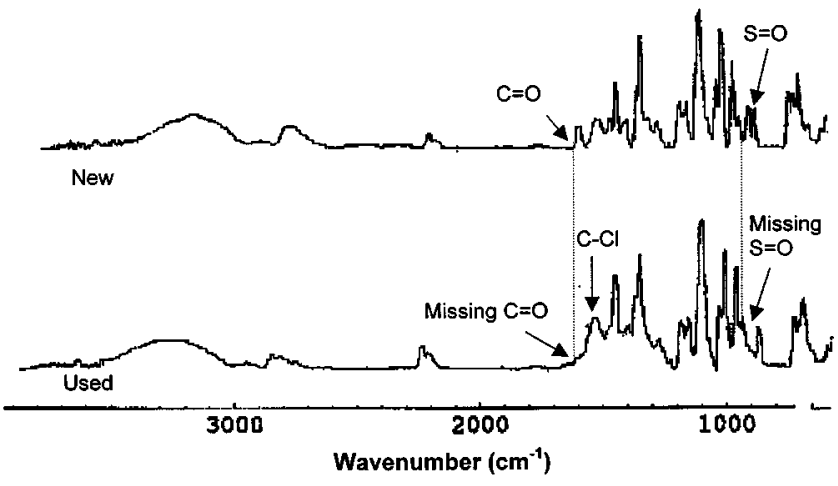

(b)

FIG. 5. (a) FTIR scans of new and used CALP, (b) FTIR scans of new and used LFC1. (Note: missing peaks are to the right of each dotted line.)

nism of chlorine-polymer interaction and subsequent membrane failure is not, as yet, clearly understood.

FTIR has proven to be a worthy complement to XPS scans. FTIR has been used to confirm XPS spectral analysis of polymers grafted from aqueous solutions to membrane surfaces. $^{29}$ FTIR has also been used to identify the fouling layers of membranes during autopsies. ${ }^{30}$ The placement and intensity of peaks for chemical groups in the FTIR scans agreed entirely with XPS data.

\section{CONCLUSIONS}

XPS and FTIR provided valuable information in identifying the causes of membrane failure during pilot operation. XPS and FTIR were especially adept at predicting surface chemical structures and highlighting areas that had been chemically changed. SEM/EDS also offered graphic evidence of the changes in surface topography. By using these methods, it was possible to confirm biological degradation to the CALP membrane. Oxidative degradation of the LFC1 membrane by chlorine was also clearly verified by these surface analytical techniques.

Analysis of chemical changes raised questions about fundamental mechanisms of membrane failure. Of particular interest in this study were the digestion of the CALP membrane by micro-organisms and the chlorination of the polyamide membranes. More research needs to be done to elucidate the mechanisms of chlorine uptake. Understanding membrane failure can lead to the production of better mem- branes, eventually making membrane technology the treatment of choice among municipal water treatment authorities.

\section{ACKNOWLEDGMENTS}

The authors would like to acknowledge the use of UCFCirent Materials Characterization Facility and the Materials Science Laboratory at the National Aeronautics and Space Administration's Kennedy Space Center. The technical assistance of Stan Young, Jaime Palou, Kirk Scammon and Satyajit V. Shukla is greatly appreciated. Sincere appreciation is also extended to Dr. James Taylor and Robert Reiss of UCF's Environmental Engineering Laboratory for providing membrane samples and background information on the pilot study. Sharon Beverly is the recipient of a graduate fellowship from the Advanced Materials Processing and Analysis Center at UCF, and the Dorothy Hoffman Award.

${ }^{1}$ J. Kruithof, P. Kamp, J. van der Hoek, J. Taylor, J. Schippers, K. Hagen, S. Adham, R. Trussel, P. Gagliardo, and A. Olivieri, Water Supply 16, 313 (1998).

${ }^{2}$ J. Jacangelo, N. Patania, and R. Trussell, Civil Engineering 68 (1989).

${ }^{3}$ J. Glater, S. Hong, and M. Elimelich, Desalination 95, 325 (1994).

${ }^{4}$ S. Hong, R. Faibish, and M. Elimelech, J. Colloid Interface Sci. 196, 267 (1997).

${ }^{5}$ S. Hong and M. Elimelech, J. Membr. Sci. 132, 159 (1997).

${ }^{6}$ R. Reiss, J. Taylor, and C. Robert, Desalination 125, 97 (1999).

${ }^{7} \mathrm{~J}$. Cadotte, Evolution of Composite Reverse Osmosis Membranes, edited by D. Lloyd, Materials Science of Synthetic Membrane (ACS, Washington, DC, 1985).

${ }^{8}$ H. Lonsdale, J. Membr. Sci. 10, 81 (1982).

${ }^{9}$ R. Petersen, J. Membr. Sci. 83, 81 (1993).

${ }^{10}$ R. Kesting, Synthetic Polymeric Membranes: A Structural Perspective, 2nd ed. (Wiley, New York, 1985).

${ }^{11}$ D. Sammon, Hyperfiltration, Their Stability and Life, edited by G. Belfort, Synthetic Membrane Processes (Academic, Orlando, FL, 1984).

${ }^{12}$ B. Parekh, Reverse Osmosis Technology (Dekker, New York, 1988).

${ }^{13}$ D. Shirley, Phys. Rev. B 5, 4709 (1972).

${ }^{14}$ G. Beamson and D. Briggs, High Resolution XPS of Organic Polymers (Wiley, New York, 1992).

${ }^{15}$ D. Mukherjee, A. Kulkarni, and W. Gill, J. Membr. Sci. 97, 231 (1994).

${ }^{16}$ M. Elimelech, X. Zhu, A. Childress, and S. Hong, J. Membr. Sci. 127, 101 (1997).

${ }^{17}$ T. Barr and S. Seal, J. Vac. Sci. Technol. 5, 4709 (1992).

${ }^{18}$ S. Seal, E. Hardcastle, M. Maclaurin, L. Chen, T. Barr, and J. Klinowski, Bull. Pol. Acad. Sci., Chem. 45, 17 (1997).

${ }^{19}$ S. Seal, S. Krezoski, T. Barr, and D. Petering, J. Vac. Sci. Technol. A 15, 1235 (1997)

${ }^{20}$ S. Seal, S. Krezoski, T. Barr, D. Petering, J. Klinowski, and P. Evans, Royal Society Proceedings 263, 943 (1996).

${ }^{21}$ T. Barr, S. Seal, S. Krezoski, and D. Petering, Surf. Interface Anal. 24, 99 (1996).

${ }^{22}$ S. Seal, S. Krezoski, D. Petering, T. Barr, J. Klinowski, and P. Evans, J. Vac. Sci. Technol. A 14, 1770 (1996).

${ }^{23}$ J. Koo, R. Petersen, and J. Cadotte, ACS Polym. Prepr. 27, 391 (1986).

${ }^{24}$ Sadtler Research Laboratories, The Infrared Spectra Atlas of Monomers and Polymers, Philadelphia, 1980.

${ }^{25}$ A. Kuptsov and G. Zhizhin, Handbook of Fourier Transform Raman and Infrared Spectra of Polymers (Elsevier, Amsterdam, 1998).

${ }^{26}$ E. Pretsch, J. Seibl, and W. Simon, Spectral Data for Structure Determination of Organic Compounds (Springer, Berlin, 1989).

${ }^{27}$ R. Seymour and C. Carraher, Jr., Polymer Chemistry (Dekker, New York, 1981).

${ }^{28}$ D. Lide, CRC Handbook of Chemistry and Physics (Chemical Rubber, Boca Raton, FL, 1993).

${ }^{29}$ S. Belfer, Y. Purinson, and O. Kedem, Acta Polym. 49, 574 (1998).

${ }^{30}$ G. Khedr, Desalination 120, 107 (1998). 